\title{
Intractable chest pain in cardiomyopathy: treatment by a novel technique of cardiac cryodenervation with quantitative immunohistochemical assessment of success
}

\author{
J A R Gaer, L Gordon, J Wharton, J M Polak, K M Taylor, W McKenna, D J Parker
}

\begin{abstract}
A novel method of cardiac denervation by cryoablation has been developed experimentally. The technique uses liquid nitrogen delivered under pressure to ablate the principal sources of cardiac innervation-namely, the adventitia surrounding the aorta, pulmonary arteries, and veins. The technique has been verified experimentally both in vivo by physiological means and in vitro by quantitative immunohistochemistry and the measurement of myocardial noradrenaline concentrations. A 35 year old woman presented with intractable precordial pain, normal epicardial coronary arteries, and hypertrophic cardiomyopathy. Her symptoms were refractory to maximal medical treatment and she was thought to be unsuitable for either conventional myocardial revascularisation, autotransplantation, or allografting with the concomitant risk of transplant coronary artery disease. She therefore underwent cardiac denervation by the method developed in the laboratory. There was quantitative immunohistochemical evidence of extrinsic cardiac denervation associated with a considerable improvement in her symptoms. This improvement persisted during a follow up period of over 16 months.
\end{abstract}

(Br Heart f 1993;70:574-577)

\section{Case report}

A 35 year old woman presented initially in 1985 with a two week history of cough, anorexia, nausea, and lethargy. An apical systolic murmur was noted and echocardiography suggested hypertrophic cardiomyopathy. She was then lost to follow up but returned in 1989 with a two year history of chest pain. This had been diagnosed as angina secondary to hypertrophic cardiomyopathy. Treatment with diltiazem, verapamil, and $\beta$ blockers did not improve her symptoms. She was fitted with an AV sequential pacemaker because of her worsening exercise tolerance, but this too was of no benefit.

She was first seen by us in June 1990 when she described episodes of chest pain, usually on exertión but also at rest and at night. The pain occurred up to 10 times daily and her exercise tolerance had deteriorated from four miles to 200 yards. Although she denied paroxysmal nocturnal dyspnoea, she slept with three pillows. Her medication at this time consisted of sotalol ( $80 \mathrm{mg}$ twice daily) and verapamil (240 $\mathrm{mg}$ twice daily). She had four children (aged 6, 8, 10, and 11 years) all of whom were healthy. She was unaware of a family history of hypertrophic cardiomyopathy, although two members of her family had died suddenly in middle age. On admission a soft pansystolic murmur and considerable obesity were noted.

\section{INVESTIGATIONS}

Haematological and biochemical variables were normal. A resting 12 lead electrocardiogram showed $T$ wave inversion in leads $I$, aVL, and V4-V6, and her chest $x$-ray film on admission was normal. A transthoracic echocardiogram showed considerable concentric hypertrophy, good posterior movement, and a small end systolic volume. Left heart catheterisation showed normal coronary arteries with no left ventricular outflow tract gradient and a left ventricular end diastolic pressure of $24 \mathrm{~mm} \mathrm{Hg}$ (table 1). The patient managed five minutes of a Bruce protocol during which time her blood pressure fell from $120 / 80 \mathrm{~mm} \mathrm{Hg}$ to $100 / 50 \mathrm{~mm} \mathrm{Hg}$. There were no significant ST-T wave changes. Her $\mathrm{VO}_{2} \max$ was $17.0 \mathrm{ml} / \mathrm{min} / \mathrm{kg}$ with a respiratory quotient of $1 \cdot 03$. Thallium exercise tests showed increased apical uptake of isotope with reverse redistribution on delayed scanning suggestive of reversible ischaemia. Oesophageal manometry and a

Table 1 Preoperative and postoperative left and right heart catheterisation pressures $(\mathrm{mm} \mathrm{Hg}$ )

\begin{tabular}{lll}
\hline & Preoperative & Postoperative \\
\hline PA (mean) & $30 / 18(20)$ & $20 / 6(8)$ \\
PAW & 17 & 6 \\
LV systolic & 120 & 120 \\
Aorta (mean) & $120 / 70(90)$ & $120 / 75(95)$ \\
LVEDP & 24 & 12 \\
\hline
\end{tabular}

PA, pulmonary artery; PAW, pulmonary artery wedge; LV, left ventricular; LVEDP, left ventricular and diastolic pressure. 
Bernstein's test were unequivocally normal. Coronary flow reserve was assessed with intra-arterial adenosine. This showed an increase in coronary flow of $10 \%$ compared with a predicted increase of $300 \%-400 \%$. On the basis of this information the presumptive diagnosis was one of a hypertrophic cardiomyopathy with angina due to an abnormality of vasomotor control.

\section{MANAGEMENT}

A variety of medical manoeuvres were attempted, including manipulation of the AV delay on her pacemaker (with exercise tests before and after), high dose diltiazem treatment $(720 \mathrm{mg} /$ day), and medium dose diltiazem treatment with added captopril and dipyridamole. Transcutaneous nerve stimulation with a temporary dorsal column nerve stimulator at the level of the sixth cervical vertebra was attempted at frequencies of stimulation ranging from $35-120 \mathrm{~Hz}$ over a period of one week. None of these measures relieved the symptoms. Ultimately, the patient consented to undergo complete cardiac denervation by the technique described here.

\section{OPERATIVE TECHNIQUE}

The heart was exposed through a median sternotomy. The left ventricle seemed moderately hypertrophied overall, but the apex was virtually non-contractile. Although the technique is performed in animals without it, we elected to use cardiopulmonary bypass to carry out the extensive disection and manipulation of the heart that was required. Bypass was established between bicaval venous and ascending aortic cannulation. The right atrial appendage and free wall of the right ventricle were biopsied before any dissection was started. These biopsy specimens were subsequently subjected to quantitative immunohistochemical analysis. The aorta, pulmonary artery, and superior and inferior venae cavae were fully mobilised. The adventitia was stripped from $5 \mathrm{~cm}$ of the ascending aorta. The interatrial groove was mobilised to give access to the transverse sinus and allow mobilisation of the pulmonary veins. Lengths of polyvinyl chloride (PVC) tubing were threaded around the pulmonary veins and the ascending aorta in an identical manner to that described in animal models. ${ }^{12}$ These were connected in turn to a modified Dewar flask containing liquid nitrogen. Compressed air was pumped into the Dewar flask to deliver liquid nitrogen under pressure into the PVC tubing. This process was carried out on two occasions for three minutes each with both tubes. Cardiopulmonary bypass was discontinued without incident.

The patient made an uneventful recovery and was discharged from hospital on the twelfth postoperative day, having been free from pain since the operation.

\section{FOLLOW UP}

When reviewed about six weeks after surgery, the patient reported a dramatic improvement in her symptoms, having had no significant chest pain since the operation. Associated with this, however, she reported a worsening of her dyspnoea. Left and right heart catheterisation was repeated about six months after the operation (table 1). It is of interest that, despite her increased breathlessness, both her pulmonary capillary wedge and left ventricular end diastolic pressures had fallen considerably. Her $\mathrm{VO}_{2} \max$ was $14 \mathrm{ml} / \mathrm{min} / \mathrm{kg}$, there were no ST-T wave changes and her blood pressure response was normal. Thallium scanning showed no defects but radionuclide assessment of systolic function showed a fall in ejection fraction from $71 \%$ to $55 \%$.

\section{IMMUNOHISTOCHEMICAL ANALYSIS}

Biopsy specimens were taken from the right ventricle at the time of surgery and at 11 and 39 days postoperatively. Also the right atrial appendage was removed before denervation. These specimens were subjected to immunohistochemical analysis with the techniques that we have described in detail elsewhere. ${ }^{3}$ Briefly, biopsy specimens were fixed immediately in a modified Bouin's solution ${ }^{4}$ for one to three hours and an indirect immunofluorescence technique was used to localise the general neural marker protein PGP 9.5 and the regulatory peptide neuropeptide $Y$ (NPY). After staining with established antisera to PGP 9.5 and NPY, the slides were subjected to quantitative immunohistochemical analysis with a Kontron VIDAS (Kontron Electronik Ltd, Watford) image processing system, interfaced to an Olympus AH-2 microscope through a low light video camera. Measurements of total field area (myocardium) and segmented area (immunofluorescent nerves) were obtained for each field and the percentage fluorescent area derived for each immunostained section. All fields were measured for each preparation and comparative measurements were made of myocardial innervation alone.

\section{STATISTICS}

All data are presented as the mean and $95 \%$ confidence interval $(95 \% \mathrm{CI})$. The proportion of immunoreactive nerve subtypes in innervated and denervated myocardium were compared by analysis of variance of $\log$ transformed data. A p value $<0.05$ was considered to be significant.

\section{RESULTS OF IMMUNOHISTOCHEMICAL}

ANALYSIS

Autonomic and sensory cardiac innervation was visualised with an antiserum to the general neural marker PGP 9.5. Scattered immunofluorescent nerve fibres were seen in the myocardium of endomyocardial biopsy sections before denervation (figure, $A$ and $C$ ). The immunofluorescent area occupied by these nerves was reduced by about $50 \%(\mathrm{p}=$ $0.0067) 11$ days after cryoablation (table 2). Immunoreactive nerve fibres were even more sparse at 39 days after operation (figure B and D), by which time the immunofluores- 
Table 2 Mean percentage of the fluorescent areas of nerves displaying PGP 9.5-like immunoreactivity before and after cryodenervation

\begin{tabular}{ll}
\hline $\begin{array}{l}\text { Time after } \\
\text { surgery (days) }\end{array}$ & $\begin{array}{l}\text { Fluorescent nerve } \\
\text { area }(95 \% \mathrm{CI})\end{array}$ \\
\hline 0 & $0.47(0.26-0.68)$ \\
11 & $0.24^{\star}(0.15-0.33)$ \\
39 & $0.10^{\star \star}+(0.05-0.16)$ \\
\hline${ }^{\star} \mathrm{p}=0.0067 ; \quad{ }^{\star \star} \mathrm{p}=0.0024$ & compared with before
\end{tabular}
${ }^{\star} \mathrm{p}=0.0067 ;$
denervation. $t \mathrm{k}=0.0083$ compared with 11 days after denervation.

Each value represents the mean fluorescent nerve area of 16 , 30 , and 20 distinct fields in sections of biopsy specimens obtained at 0,11 , and 39 days.

cent area had fallen to less than $25 \%$ ( $p=$ 0.0024 ) of the value before denervation (table 2).

In biopsy specimens taken before denervation nerve fibres with NPY-like immunoreactivity showed a similar distribution to those with PGP 9.5-like immunoreactivity with a mean percentage fluorescent area of $0.42 \%$ $(0.21 \%-0.64 \%)$. No nerves with NPY-like immunoreactivity were detected in biopsy specimens obtained at 11 and 39 days after operation (figure).

When the right atrial appendage was examined, the mean percentage fluorescent area occupied by nerves with PGP 9.5-like immunoreactivity was $5 \cdot 15 \% \quad(4 \cdot 59 \%$ $5 \cdot 71 \%$ ), whereas the mean percentage fluorescent area occupied by nerves with NPY-like immunoreactivity was $3.61 \%$ $(2 \cdot 94 \%-4 \cdot 29 \%)$.

\section{Discussion}

Complete cardiac denervation is a consequence of orthotopic transplantation and has been shown clinically and histologically, ${ }^{4-6}$ and although there is now some evidence of reinnervation of human cardiac allografts, this is at best incomplete and certainly delayed. ${ }^{78}$ Chronic extrinsic denervation, achieved by one of a number of means, has been used for many years in the study of cardiac transplant physiology, ${ }^{9-11}$ but it was considered that such an approach would carry a higher risk than cryoablation, which has also been used for cardiac denervation in animal models. ${ }^{12}$ In the laboratory these techniques have the advantage of being simple to perform and consistently achieve complete denervation. ${ }^{3}$ This is the first report of cryoablation techniques being used to produce cardiac denervation in a human being. The woman in question is young, with hypertrophic cardiomyopathy and intractable chest pain. Although she clearly had impaired coronary flow reserve, as shown by the intracoronary infusion of adenosine, her epicardial coronary arteries were considered to be unequivocally normal. Thus conventional methods of myocardial revascularisation would have been inappropriate. Similarly, it would have been unreasonable to expose her to the dangers of conventional allografting with the attendant risk of transplant coronary artery disease. The alternative therefore would have been cardiac autotransplantation. This has the advantage of ensuring complete extrinsic denervation but is an operation that is in itself not without risk. Autotransplantation has been used in the past to treat variant angina, but the results have been unpredictable. ${ }^{12}$

Several methods have been used to verify the completeness of extrinsic cardiac denervation. These include functional tests, ${ }^{5}$ histochemical and electron microscopical studies, ${ }^{1314}$ measurement of the uptake of an analogue of a precursor of noradrenaline by positron emission tomography, ${ }^{7}$ measurement of the coronary sinus concentration of noradrenaline in response to the intracoronary
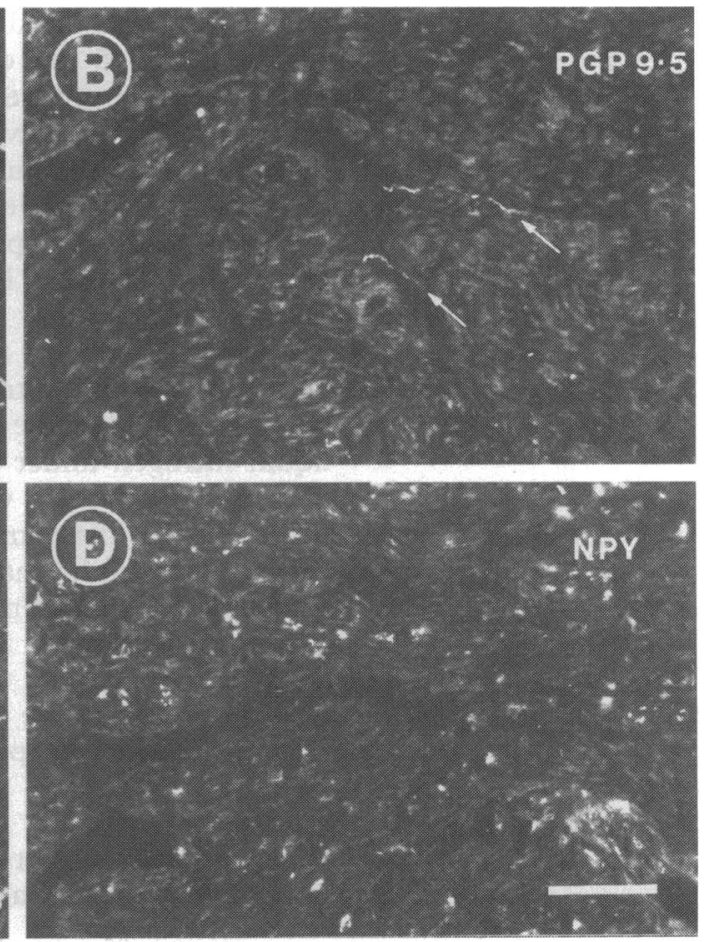

Density of $P G P 9 \cdot 5$ and NPY immunoreactive nerves before ( $A$ and $C$ ) and after ( $B$ and $D)$ cryodenervation, with considerable reduction in the density of nerve fibres displaying PGP 9.5-like immunoreactivity and the complete loss of nerves displaying NPY-like immunoreactivity after cryoablation.
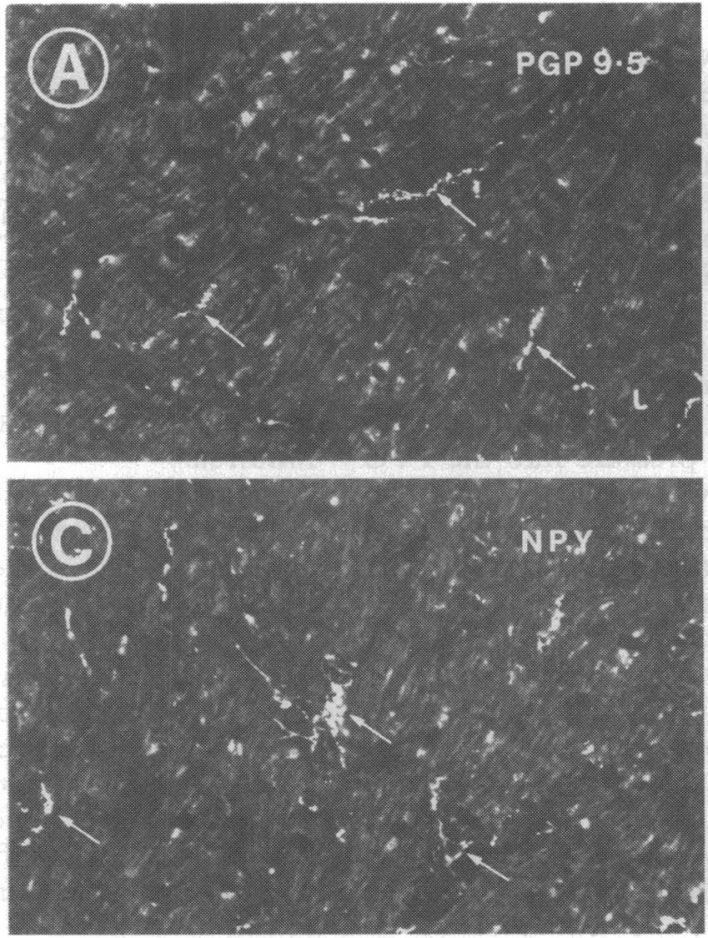
administration of tyramine, ${ }^{8}$ and the measurement of myocardial noradrenaline concentration. ${ }^{2} 1516$ Although myocardial noradrenaline concentration has been used to verify the completeness of extrinsic denervation in our animal model, ${ }^{1}$ it was not feasible in this study because of the small size and limited number of endomyocardial biopsy specimens available for assay. We have not conducted any physiological tests of denervation but have been able to document a dramatic amelioration of her symptoms. The immunohistochemical methods that we have used to show the extent of myocardial innervation before and after cryodenervation is one that we have fully evaluated in the past. ${ }^{3}$ The advantage of this method is that cardiac nerves may be seen directly. Furthermore, endomyocardial biopsies are routinely performed in any centre undertaking cardiac transplantation and are less invasive, for instance, than the intracoronary injection of tyramine.

PGP 9.5 is a $27 \mathrm{kDa}$ protein originally isolated from human brain ${ }^{17}$ and shown to be a marker of vertebrate neurones and neuroendocrine cells, ${ }^{18}$ as well as of the mammalian cardiovascular innervation. ${ }^{3419}$ The percentage of the fluorescent area occupied by nerves displaying PGP 9.5-like immunoreactivity is, therefore, an indication of the total innervation of the myocardium. Comparison of the results of staining with PGP 9.5 in the right atrial appendage with those obtained from the right ventricle before denervation shows that the myocardial innervation exhibits an atrial to ventricular gradient similar to that seen previously. ${ }^{4}$ On examination of the density of innervation in sequential right ventricular biopsies, it was evident that neuronal degeneration was incomplete at 11 days, as a further significant reduction in the density of PGP 9.5 was seen at 39 days after operation.

That the nerves displaying NPY-like immunoreactivity disappeared completely after denervation suggests that they are extrinsic in origin, which is consistent with the view that nerves containing NPY represent the postganglionic sympathetic fibres that have synapsed in the thoracic sympathetic ganglia. ${ }^{20-22}$ These findings agree with those obtained after both cryosurgical denervation of bovine hearts ${ }^{3}$ and transplantation of human hearts. ${ }^{4}$ An unexplained finding in this patient has been the development of breathlessness after denervation. This may be related to the unexpected finding that the patient was pregnant when reviewed. When last seen, some 16 months after surgery, she remained free of pain and was again pregnant, having had a second trimester abortion in the previous pregnancy.

In conclusion, we have been able to show complete extrinsic denervation on the basis a dramatic reduction in the density of nerves exhibiting immunoreactivity for the general neural marker PGP 9.5 together with the abolition of nerves displaying NPY-like immunoreactivity. The remaining nerves are probably intrinsic in origin. This denervation has been accompanied by a dramatic improvement in the patient's symptoms, which is in keeping with the view that her pain was angina due to an abnormality of vasomotor control of microvascular coronary arteries.

This work was supported by the British Heart Foundation and the Council for Tobacco Research (NY, USA). We thank Mrs Jenny Beckett and Mr John Brannan for their assistance.

1 Gaer JAR, Wharton J, Gordon L, et al. Cardiac denervation in the calf using cryoablation: functional evidence tion in the calf using cryoablation: functional evidence Cardiothorac Surg 1992;6:201-8.

2 Douglas JM, Swain ME, Slotkin TA, Smith PK, Cox JL Cryosurgical denervation of the heart: acute and chronic Cryosurgical denervation of the heart: acute and ch
effects. F Thorac Cardiovasc Surg 1990;100:198-209.

3 Gordon L, Wharton J, Gaer JAR, Inglis GC, Taylor KM, Polak JM. Quantitative immunohistochemical assessment of bovine myocardial innervation before and after cryosurgical cardiac denervation. Cardiovasc Res 1993; 27:318-26.

4 Wharton J, Polak JM, Gordon L, et al. Immunohistochemical demonstration of human cardiac innervation before and after transplantation. Circ Res 1990; 66:900-12.

5 Mason JW, Harrison DC. Electrophysiology and electropharmacology of the transplanted human heart. In Narula OS, ed. Cardiac arrhythmias: electrophysiology diagnosis and management. Baltimore: Williams and Wilkins Co, 1979:66-81

6 Schroeder JS. Hemodynamic performance of the human transplanted heart. Transplant Proc 1979;11:304-8.

7 Schwaiger M, Hutchins GD, Kalff V, et al. Evidence for regional catecholamine uptake and storage sites in the transplanted human heart by positron emission tomotransplanted human heart by positron

8 Wilon RF, Christensen BV, Olivari MT, Simon A, White CW, Laxson DD. Evidence for structural sympathetic reinnervation after orthotopic cardiac transplantation in humans. Circulation 1991;83:1210-20

9 Cooper T, Gilbert JW, Bloodwell RD, Crout JR. Chronic extrinsic cardiac denervation by regional neural ablation. Circulation Res 1961;9:275-81.

10 Donald DE, Shepherd JT. Response to exercise in dogs with cardiac denervation. Am f Physiol 1963;205: 393-400.

11 Geis WP, Tatooles CJ, Kaye MP, Randall WC. Complete cardiac denervation without transplantation: a simple and reliable technique. 7 Appl Physiol 1971;30:289-93.

12 Bertrand ME, Lablanche JM, Tilmant PY, et al. Complete denervation of the heart (autotransplantation) for treatment of severe refractory coronary spasm. Am $\mathcal{F}$ Cardiol 1981;47:1375-8.

13 Rowan RA, Billingham ME. Myocardial innervation in long-term heart transplant survivors: a quantitative ultrastructural survey. $\mathcal{f}$ Heart Transplant 1988;7: 448-52.

14 Milam JD, Shipkey FJ, Lind CJ, et al. Morphologic findings in human cardiac allografts. Circulation 1970; 41(3):519-35.

15 Regitz V, Bossaller C, Strasser R, Schuler S, Hetzer R, Fleck E. Myocardial catecholamine content after heart ransplantation. Circulation 1990;82(2):620-3.

16 Williams TDM, Walsh KP, Canepa-Anson R, et al. Atrial natriuretic peptide response to rapid atrial pacing in car diac denervated dogs. Am $\mathcal{F}$ Physiol 1989;257:R1 62-7.

17 Jackson P, Thompson RJ. The demonstration of new brain-specific proteins by high resolution two-dimensional polyacrylamide gel electrophoresis. $f$ Neurol $S c i$ 1981;49:429-38

18 Thompson RJ, Doran JF, Jackson P, Dhillon AP, Rode J. PGP 9.5-a new marker for vertebrate neurones and neuroendocrine cells. Brain Res 1983;278:224-8.

19 Gulbenkian S, Wharton J, Polak JM. The visualisation of cardiovascular innervation in the guinea pig using an
antiserum to protein gene product 9.5 (PGP 9.5). $f$ Auton Nerv Syst 1987;18:235-47.

20 Franco-Cereceda A, Lundberg JM, Hökfelt T. Somatostatin: an inhibitory parasympathetic neurotransmitter in the human heart? Eur $\mathcal{F}$ Pharmacol 1986; 132:101-2.

21 Lundberg JM, Terenius L, Hökfelt $T$, et al. Neuropeptide $Y$ (NPY)-like immunoreactivity in peripheral noradrenergic neurons and effects of NPY on sympathetic drenergic neurons and effects of NPY on sysiol Scand 1982;116:331-40.

22 Lundberg JM, Saria A, Franco-Cereceda A, Hökfelt T, Terenius L, Goldstein M. Differential effects of reserTerenius $L$, Goldstein $M$. Differential effects of reser-
pine and 6-hydroxydopamine on neuropeptide $Y$ (NPY) and noradrenaline in peripheral neurons. Naunynand noradrenaline in peripheral neurons. 